\title{
High levels of DEPDC1B predict shorter biochemical recurrence-free survival of patients with prostate cancer
}

\author{
SHOUMIN BAI ${ }^{1,2^{*}}$, TING CHEN $^{1,2^{*}}$, TAO DU $^{2,3^{*}}$, XIANJU CHEN $^{2,4}$, YIMING LAI $^{4}$, \\ XIAOMING MA ${ }^{4}$, WANHUA WU ${ }^{4}$, CHUNHAO LIN ${ }^{4}$, LEYUAN LIU ${ }^{5,6}$ and HAI HUANG ${ }^{2,4,5}$ \\ ${ }^{1}$ Department of Radiation Oncology; ${ }^{2}$ Guangdong Provincial Key Laboratory of Malignant Tumor Epigenetics and Gene \\ Regulation; Departments of ${ }^{3}$ Obstetrics and Gynecology and ${ }^{4}$ Urology, Sun Yat-Sen Memorial Hospital, \\ Sun Yat-Sen University, Guangzhou, Guangdong 510120, P.R. China; ${ }^{5}$ Center for Translational \\ Cancer Research, Texas A\&M Institute of Biosciences and Technology; ${ }^{6}$ Department of Molecular and \\ Cellular Medicine, College of Medicine, Texas A\&M University, Houston, TX 77030, USA
}

Received November 4, 2016; Accepted March 28, 2017

DOI: $10.3892 / \mathrm{ol} .2017 .7027$

\begin{abstract}
DEP domain-containing protein 1B (DEPDC1B) has been reported to serve important functions in breast cancer and non-small cell lung cancer. However, its involvement in the development of prostate cancer (PCa) remains unclear. Therefore, the present study aimed to investigate the expression and clinical significance of DEPDC1B in tumor tissues from patients diagnosed with PCa. A total of 80 prostate tissue samples were collected following prostatectomy to generate a tissue microarray for immunohistochemical analysis of DEPDC1B protein expression. High throughput sequencing of mRNAs from 179 prostate tissue samples, either from patients with PCa or from healthy controls, was included in the Taylor dataset. The expression levels of DEPDC1B in tumor tissues from patients with $\mathrm{PCa}$ were revealed to be significantly increased compared with those in normal prostate tissues $(\mathrm{P}=0.039)$. Increased expression of DEPDC1B was significantly associated with advanced clinical stage $(\mathrm{P}=0.006)$, advanced $\mathrm{T}$ stage $(\mathrm{P}=0.012)$ and lymph node metastasis $(\mathrm{P}=0.004)$. Kaplan-Meier analysis demonstrated that patients with high levels of DEPDC1B mRNA had significantly shorter biochemical recurrence (BCR)-free survival times.
\end{abstract}

Correspondence to: Dr Hai Huang, Department of Urology, Sun Yat-Sen Memorial Hospital, Sun Yat-sen University, 107W Yanjiang Road, Guangzhou, Guangdong 510120, P.R. China

E-mail: huanghai257@126.com

Dr Leyuan Liu, Center for Translational Cancer Research, Texas A\&M Institute of Biosciences and Technology, Texas A\&M University, 2121 West Holcombe Boulevard, Houston, TX 77030, USA

E-mail:1liu@ibt.tamhsc.edu

${ }^{*}$ Contributed equally

Key words: DEP domain-containing protein 1B, prostate cancer, prognosis, progression
Multivariate analysis using Cox proportional hazards model revealed that levels of DEPDC1B mRNA were significant independent predictors of BCR-free survival time of patients with PCa. Therefore, the expression of DEPDC1B may be used as an independent predictor of biochemical recurrence-free survival time of patients with $\mathrm{PCa}$.

\section{Introduction}

Prostate cancer (PCa) is the most common cancer of the male urogenital system and the second leading cause of cancer-associated mortality in the US (1). In China, the incidence and mortality of PCa have been continually increasing (2). Although treatment modalities for this cancer have improved, predicting the clinical outcome of $\mathrm{PCa}$ remains difficult (3). Biochemical recurrence (BCR) occurs in $\sim 20 \%$ of patients with PCa following radical prostatectomy or radiotherapy (4). A series of clinical parameters, including serum prostate-specific antigen (PSA) levels, Gleason score and surgical margin status, in various combinations, have been used to predict the outcome for PCa $(5,6)$. However, the ability of conventional prognostic factors to identify insignificant $\mathrm{PCa}$ may be limited (7). Therefore, it is important to identify more novel and sensitive PCa molecular markers that are associated with biological aggressiveness and able to provide valuable information for the diagnosis and treatment of the disease.

Located at chromosome 5 (5q12.1), the DEP domaincontaining protein $1 \mathrm{~B}$ (DEPDC1B) gene encodes a protein containing two structural domains: A DEP domain and a RhoGAP domain (8-10). The DEP domain enables the protein to interact with $\mathrm{G}$ protein coupled receptors as well as negatively-charged membrane phospholipids, and the RhoGAP domain is responsible for Rho GTPase signaling (9-11). The precise function of DEPDC1B is uncharacterized. It has been reported to be associated with regulating cellular activities, including cell growth, movement, differentiation, cell cycle and reorganization of cytoskeleton (10). Subsequent studies demonstrated that DEPDC1B is also overexpressed in other types of cancer, including breast cancer (12), oral cancer (13) and non-small cell lung cancer (14), and is a prognostic factor 
that predicts outcomes in patients with non-small cell lung cancer (14). The potential prognostic value of DEPDC1B in patients with $\mathrm{PCa}$ remains unknown. Therefore, the present study examined the expression of DEPDC1B in prostate tissues, using immunohistochemistry to explore its clinical significance.

In the present study, DEPDC1B expression in a tissue microarray (TMA) containing 80 samples was examined. In order to investigate the expression of DEPDC1B at the mRNA level and perform survival analysis, the clinical information of the Taylor dataset (15), including 150 prostate cancer tissues and 29 normal prostate tissue, was also collected. The association between the relative expression of DEPDC1B and clinicopathological parameters was examined to evaluate its clinical significance. In addition, the impact of DEPDC1B expression on the biochemical recurrence (BCR) of patients with PCa was assessed.

\section{Materials and methods}

Patients and tissue samples. For immunohistochemical analysis, a TMA ( $\mathrm{n}=80$; catalog no. PR803c), including 73 tumor tissue samples from patients with $\mathrm{PCa}, 3$ adjacent normal prostate tissue samples from patients with $\mathrm{PCa}$ and 4 normal prostate tissue samples from healthy donors, and detailed clinical information were obtained from Alenabio Biotechnology Ltd. (Xi'an, China), a distributor of US Biomax, Inc. (Rockville, MD, USA) in China. Patients who received chemotherapy or radiotherapy prior to surgery were excluded from the present study. In order to investigate the expression of DEPDC1B at the mRNA level and perform survival analysis, the clinical information of the Taylor dataset, including 150 prostate cancer tissue samples and 29 normal prostate tissue samples, was also collected (15). All patients were followed up for 13 months or longer. Detailed information on the clinical features of all patients and healthy controls in the present study is summarized in Table I. All procedures performed in studies involving human patients were in accordance with the ethical standards of the institutional and/or national research committee and with the 1964 Helsinki declaration and its later amendments or comparable ethical standards. The present study is a retrospective study in accordance with ethics review regulations and was reviewed and approved by the Ethics Committee, Sun Yat-sen Memorial Hospital, Sun Yat-sen University (Guangzhou, China) on December 26th, 2015.

Immunohistochemical analysis (IHC). The specimens were fixed in $10 \%$ neutral buffered formalin at room temperature for $12 \mathrm{~h}$ and subsequently embedded in paraffin. The paraffin-embedded tissues were cut into $4 \mu \mathrm{m}$ sections and then deparaffinized with xylene and rehydrated (100\% ethanol twice for $10 \mathrm{~min}, 95 \%$ ethanol for $5 \mathrm{~min}, 80 \%$ ethanol for $5 \mathrm{~min}$ and $70 \%$ ethanol for $5 \mathrm{~min}$ ) for blocking of endogenous peroxidase activity, 3,3'-diaminobenzidine (DAB) staining and IHC using the Dako EnVision system (Dako; Agilent Technologies, Inc., Santa Clara, CA, USA). Following a brief proteolytic digestion (0.1\% trypsin; no. ZLI9010; Beijing Zhongshan Golden Bridge Biotechnology Co., Ltd., Beijing, China) and peroxidase blocking $\left(3 \% \mathrm{H}_{2} \mathrm{O}_{2}\right.$, no. HPBIO-JX170, HePeng Biology, Shanghai, China) at $37^{\circ} \mathrm{C}$ for $10 \mathrm{~min}$, tissue slides were incubated with the primary antibody against DEPDC1B (rabbit polyclonal antibody, cat. no. bs-14278R; BIOSS, Beijing, China) at a dilution of 1:600 at $4^{\circ} \mathrm{C}$ overnight. Following washing (PBS for $5 \mathrm{~min}, 3$ times), peroxidase-labeled polymer mouse anti-rabbit antibodies (cat. no. 3678S; Cell Signaling Technology, Inc., NY, USA; 1:20,000; at $37^{\circ} \mathrm{C}$ for $1 \mathrm{~h}$ or at $4^{\circ} \mathrm{C}$ overnight) and substrate-chromogen staining (DAB, no. 9018, Beijing Zhongshan Golden Bridge Biotechnology Co., Ltd., Beijing, China) were employed in order to visualize the protein. Negative controls were performed by omitting the primary antibody.

Evaluation of immunostaining results. The intensity of immunostaining was scored separately by two independent experienced pathologists, who were blinded to the clinicopathological data and clinical outcomes of the patients. The scores of the two pathologists were compared and any discrepancies were resolved through re-examination of the staining by the two pathologists to achieve a consensus score. The immunolabeling of cancer cells was then evaluated. The number of positive-staining cells in five representative fields at 400-fold were counted under an inverted microscope and the percentage of positive cells was also calculated. According to the antibody specification sheet, cytoplasmic staining was regarded as positive signals. The semi-quantitative scoring of the expression intensity in each sample was performed according to a previous study and was based on the staining intensity and percentage (16). The staining intensity was visually scored and stratified according to the following criteria: No staining, 0 points; mild staining, 1 point; moderate staining, 2 points and strong staining, 3 points. The score for the percentage of immunoreactive tumor cells was defined as follows: $<5 \%$, 0 points; $6-25 \%, 1$ point; $26-50 \%, 2$ points; $51-75 \%, 3$ points and $>75 \%, 4$ points. The final immunoreactivity scores (IRS) of each sample was calculated by adding the two scores for the immunostaining intensity and immunostaining percentage. An IRS score $<4$ was defined as low expression and $\geq 4$ was defined as high expression.

Assays of levels of DEPDCIB $m R N A$ and protein in prostate cell lines. Normal prostate epithelial cell (RWPE1), androgen-dependent prostatic carcinoma cell (LNcap) and androgen-independent prostatic carcinoma cells (DU145 and PC-3) were used in the present study. RWPE1, LNcap, DU145 and PC-3 cell lines were obtained from the Center for Experimental Animals of Sun Yat-Sen University. The cells were maintained in RPMI-1640 (Gibco; Thermo Fisher Scientific, Inc., Waltham, MA, USA) supplemented with $10 \%$ fetal bovine serum, $1 \%$ penicillin and streptomycin (all Invitrogen; Thermo Fisher Scientific, Inc.). The RWPE1 cell line was maintained in complete keratinocyte serum-free medium supplemented with $50 \mathrm{mg} / \mathrm{ml}$ bovine pituitary extract and $5 \mathrm{ng} / \mathrm{ml}$ epidermal growth factor (all Gibco; Thermo Fisher Scientific, Inc.). All cell lines were cultivated in a humidified incubator at $37^{\circ} \mathrm{C}$ with $5 \% \mathrm{CO}_{2}$. Total RNA was extracted from cultured prostate cells ( $\sim 5 \times 10^{6}$ cells), including LNcap, DU145, PC3 and RWPE-1. The Invitrogen SuperScript III First-Strand System (Invitrogen; Thermo Fisher Scientific, Inc.) was used for reverse transcription (RT) with random primers [Hexadeoxyribonucleotide mixture; pd (N)6; cat. no. 3801; 
Takara Biotechnology Co., Ltd., Dalian, China]. Quantitative polymerase chain reaction analysis was performed with SYBR Premix ExTaq (Takara RR820A; Takara Biotechnology Co., Ltd.). Real-time PCR primers were as follows: DEPDC1B forward, 5'-AGCTACCAGGCTGTGGAATG-3' and reverse, 5'-AGCTCTTGAAACGACAGCGA-3'; GAPDH forward, 5'-TGGTCGTATTGGGCGCCTGGT-3' and reverse, 5'-TCG CTCCTGGAAGATGGTGA-3'. Amplification was achieved using the following protocol: $48^{\circ} \mathrm{C}$ for $30 \mathrm{~min}, 95^{\circ} \mathrm{C}$ for $1 \mathrm{~min}$ followed by 40 cycles at $95^{\circ} \mathrm{C}$ for $15 \mathrm{sec}, 52^{\circ} \mathrm{C}$ for $30 \mathrm{sec}$ and $72^{\circ} \mathrm{C}$ for $30 \mathrm{sec}$. The relative mRNA expression levels of DEPDC1B were normalized to GAPDH mRNA. The results were calculated using the $2^{-\Delta \Delta C q}$ method (17). Cell lysates were prepared and subjected to immunoblot analysis of DEPDC1B protein. Cells $\left(\sim 1 \times 10^{7}\right)$ were washed twice with ice-cold PBS, lysed with RIPA Lysis Buffer (no. P0013B; Beyotime Institute of Biotechnology, Haimen, China) and complete protease inhibitor cocktail (no. B14001a; Selleck, Shanghai, China) on ice for $30 \mathrm{~min}$ and then cleared by centrifugation at 9,500 x g at $4^{\circ} \mathrm{C}$ for another $30 \mathrm{~min}$. The total protein concentration in the extracts were evaluated utilizing a BCA protein assay kit (Beyotime Institute of Biotechnology). Equal amounts $(30 \mu \mathrm{g})$ of protein were separated by SDS-PAGE and transferred to a polyvinylidene fluoride membrane (EMD Millipore, Billerica, MA, USA). The membranes were blocked with 5\% bovine serum albumin or non-fat dry milk in TBST at room temperature for $1 \mathrm{~h}$ and then probed with antibodies against DEPDC1B (no. bs-14278R; 1:1,000; BIOSS) and GAPDH (no. 2118; 1:20,000; Cell Signaling Technology, Inc.). The relative protein intensities of DEPDC1B to loading control GAPDH were quantified using Image $\mathrm{J}$ software (v2.1.4.7; National Institutes of Health, Bethesda, MD, USA).

Statistical analysis. SPSS 22.0 software (IBM SPSS, Armonk, NY, USA) was used for Statistical analysis. Data are presented as the mean \pm standard deviation. All of the P-values were two-sided and $\mathrm{P}<0.05$ was considered to indicate a statistically significant difference. Pearson's $\chi^{2}$ test and Fisher's exact test were used to analyze the association of DEPDC1B expression with clinicopathological characteristics. Overall survival time and BCR survival time were analyzed using the Kaplan-Meier method, and differences were assessed using the log-rank test. Receiver operating characteristic curves (ROC) revealed that the cut off of DEPDC1B mRNA levels was 6.193 and the area under the ROC was $0.732(\mathrm{P}<0.001)$. A DEPDC1B mRNA level $\geq 6.193$ was defined as high expression and $<6.193$ was defined as low expression. Univariate analysis comparisons and multivariate survival comparisons were performed using Cox proportional hazard regression models. The relative risks of mortality were expressed as adjusted hazard ratios (HRs) and their corresponding 95\% confidence intervals (CIs). $\mathrm{P}<0.05$ was considered to indicate a statistically significant difference.

\section{Results}

DEPDC1B protein is upregulated in tumor tissues of patients with PCa. The expression of DEPDC1B protein was detected in the TMA by IHC (Table I). There were 80 samples in total, and 2 samples of prostatic sarcomas and 2 lost samples were not included in the analyses. There was strong expression of DEPDC1B in the cytoplasm of cancer cells from tumor tissues, but weak expression in luminal epithelial cells of adjacent normal prostate tissues from patients with $\mathrm{PCa}$ and normal prostate tissues from healthy donors (Fig. 1). Of the 69 tumor tissue samples, 17 (24.6\%) demonstrated low levels, while 52 $(75.4 \%)$ high levels of DEPDC1B. Furthermore, the expression levels of DEPDC1B in tumor tissues were significantly increased compared with normal prostate tissues $(4.78 \pm 1.47$ and $3.33 \pm 0.51$, respectively; $\mathrm{P}=0.039$; Fig. 1 ).

Immunostaining results were analyzed using the limited clinical information of the TMA. The results revealed that the overexpression of DEPDC1B protein was significantly associated with advanced clinical stage $(\mathrm{P}=0.006$; Table I), advanced $\mathrm{T}$ stage $(\mathrm{P}=0.012$; Table $\mathrm{I})$ and lymph node metastasis $(\mathrm{P}=0.004$; Table I). However, high levels of DEPDC1B were not associated with age, pathological grade and distant metastasis $(\mathrm{P}>0.05$; Table $\mathrm{I})$.

Increased expression of DEPDCIB $M R N A$ is associated with the aggressive progression and poor prognosis of $P C a$ in the Taylor dataset. To validate the results of the present cohort, a publicly available dataset (Taylor dataset) consisting of 150 prostate tissues with mRNA micro-array expression data for protein-coding genes (mRNA) was used. DEPDC1B mRNA was upregulated in tumor tissue samples from patients with PCa with a high Gleason score $(\mathrm{P}<0.001$; Table I), advanced pathological stage $(\mathrm{P}<0.001$; Table I), high lymph node metastasis $(\mathrm{P}<0.001$; Table $\mathrm{I})$, high distant metastasis $(\mathrm{P}<0.001$; Table I) and high rate of biochemical recurrence $(\mathrm{P}<0.001$; Table I).

DEPDC1B serves as an independent prognostic factor for the survival time of patients with PCa. The association of DEPDC1B expression with the survival time of patients with PCa was analyzed by Kaplan-Meier plots and the Taylor dataset. The BCR-free survival times of patients with PCa with high levels of DEPDC1B mRNA expression were significantly shorter compared with those with low levels of DEPDC1B mRNA expression ( $\mathrm{P}=0.001)$, although no significant difference in their overall survival rate was observed $(\mathrm{P}=0.392$; Fig. 2). As the present data indicated a mortality rate of $<50 \%$, it was not possible to calculate median survival time. In addition, univariate analysis revealed that expression levels of DEPDC1B mRNA were significant prognostic factors for BCR-free survival times of patients with PCa (HR, 5.503; 95\% CI, 1.687-17.952; $\mathrm{P}=0.005$; Table II). Multivariate analysis using Cox proportional hazards model revealed that high levels of DEPDC1B mRNA expression were significant independent prognostic factors for patients with PCa (HR, 4.285; 95\% CI 1.257-14.609; $\mathrm{P}=0.020$; Table II). However, PSA is not cancer-specific, and as a biomarker has caused over-diagnosis (18). PSA demonstrated no statistical significance in Cox model analysis (Table II). Since the Taylor dataset used in the present study contained no information associated with the PSA free/total $(\mathrm{F} / \mathrm{T})$ ratio, it was not possible to explore the potential of the PSA F/T ratio for prognosis prediction.

DEPDC1B protein and $M R N A$ levels are not consistent in cultured cells. It would be ideal to obtain data about the 
Table I. Associations between DEPDC1B expression and clinicopathological characteristics of patients with prostate cancer in the TMA and Taylor database.

\begin{tabular}{|c|c|c|c|c|c|c|}
\hline \multirow[b]{2}{*}{$\begin{array}{l}\text { Clinical } \\
\text { features }\end{array}$} & \multicolumn{4}{|c|}{ TMA } & \multicolumn{2}{|c|}{ Taylor } \\
\hline & $\begin{array}{c}\text { Total } \\
\text { patients, } \mathrm{n}\end{array}$ & $\begin{array}{l}\text { Low, } \\
\text { n (\%) }\end{array}$ & $\begin{array}{l}\text { High, } \\
\mathrm{n}(\%)\end{array}$ & P-value & $\begin{array}{l}\text { Total patients, } \\
\mathrm{n}(\text { mean } \pm \mathrm{SD})\end{array}$ & $\begin{array}{l}\text { P-value } \\
\left(\chi^{2} \text { test }\right)\end{array}$ \\
\hline \multicolumn{7}{|l|}{ Tissue } \\
\hline Cancer & 69 & $31(44.9)$ & $38(55.1)$ & \multirow[t]{2}{*}{0.012} & $150(6.35 \pm 0.27)$ & \multirow[t]{2}{*}{$<0.001$} \\
\hline Benign & 6 & $6(100.0)$ & $0(0.0)$ & & $29(6.18 \pm 0.14)$ & \\
\hline \multicolumn{7}{|l|}{ Age } \\
\hline$\leq 60$ years & 16 & $10(62.5)$ & $6(37.5)$ & \multirow[t]{2}{*}{0.271} & $93(6.36 \pm 0.28)$ & \multirow[t]{2}{*}{0.950} \\
\hline$>60$ years & 59 & $27(45.8)$ & $32(54.2)$ & & $57(6.36 \pm 0.26)$ & \\
\hline \multicolumn{7}{|l|}{ PSA level } \\
\hline$\leq 4 \mathrm{ng} / \mathrm{ml}$ & - & - & - & \multirow[t]{2}{*}{-} & $34(6.29 \pm 0.24)$ & \multirow[t]{2}{*}{0.149} \\
\hline$>4 \mathrm{ng} / \mathrm{ml}$ & - & - & - & & $113(6.36 \pm 0.26)$ & \\
\hline \multicolumn{7}{|c|}{ Gleason score } \\
\hline$<7$ & - & - & - & \multirow[t]{3}{*}{ - } & $41(6.25 \pm 0.19)$ & \multirow[t]{3}{*}{$<0.001$} \\
\hline$=7$ & - & - & - & & $76(6.31 \pm 0.18)$ & \\
\hline$>7$ & - & - & - & & $22(6.59 \pm 0.40)$ & \\
\hline \multicolumn{7}{|c|}{ Pathological grade } \\
\hline$\leq 2$ & 22 & $10(45.5)$ & $12(54.5)$ & \multirow[t]{2}{*}{0.604} & $86(6.26 \pm 0.17)$ & \multirow[t]{2}{*}{$<0.001$} \\
\hline$>2$ & 44 & $20(45.5)$ & $24(54.5)$ & & $55(6.44 \pm 0.32)$ & \\
\hline \multicolumn{7}{|c|}{ Clinical stage } \\
\hline I & 42 & $25(59.5)$ & 17 (40.5) & \multirow[t]{4}{*}{0.006} & $80(6.33 \pm 0.24)$ & \multirow[t]{4}{*}{0.022} \\
\hline II & 25 & $6(24.0)$ & $19(76.0)$ & & $58(6.31 \pm 0.24)$ & \\
\hline III & & & & & $6(6.47 \pm 0.34)$ & \\
\hline IV & & & & & $1(7.01 \pm 0.00)$ & \\
\hline \multicolumn{7}{|l|}{ T stage } \\
\hline $\mathrm{T} 1-\mathrm{T} 2$ & 44 & $25(56.8)$ & $19(43.2)$ & \multirow[t]{2}{*}{0.021} & - & \multirow[t]{2}{*}{-} \\
\hline T3-T4 & 24 & $6(25.0)$ & $18(75.0)$ & & - & \\
\hline \multicolumn{7}{|c|}{ Lymph node metastasis } \\
\hline N0 & 56 & $30(53.6)$ & $26(46.4)$ & \multirow[t]{2}{*}{0.004} & $105(6.30 \pm 0.20)$ & \multirow[t]{2}{*}{$<0.001$} \\
\hline N1 & 12 & $1(8.3)$ & $11(91.7)$ & & $16(6.67 \pm 0.41)$ & \\
\hline \multicolumn{7}{|c|}{ Distant metastasis } \\
\hline M0 & 60 & $30(50.0)$ & $30(50.0)$ & 0.063 & $122(6.27 \pm 0.18)$ & $<0.001$ \\
\hline M1 & 8 & $1(12.5)$ & 7 (87.5) & & $28(6.69 \pm 0.34)$ & \\
\hline Biochemica & & & & & & \\
\hline Negative & - & - & - & - & $104(6.27 \pm 0.18)$ & $<0.001$ \\
\hline Positive & - & - & - & & $36(6.51 \pm 0.33)$ & \\
\hline
\end{tabular}

'-' suggests absence of patient-associated data in the present cohort. TMA, tissue microarray; PSA, prostate-specific antigen; SD, standard deviation.

expression levels of mRNA and protein in all patient tissue samples. However, such datasets were unavailable. Therefore, the expression levels of prostate cell lines were examined. The PCa DU145 and LNCap cell lines had higher DEPDC1B mRNA levels, while PC3 had lower DEPDC1B mRNA levels, compared with the normal prostate RWPE-1 cell line (Fig. 3A). In contrast, protein levels of all three PCa cell lines were lower than those in RWPE-1 cells (Fig. 3B and C). Thus, the results from cultured cells were unable to reflect the expression levels of DEPDC1B in tissue samples of patients with PCa.

\section{Discussion}

Patients may have different clinical courses with similar clinicopathological characteristics when being treated with the same therapy, indicating that the value of current diagnostic markers is limited. Thus, it is important to identify novel 


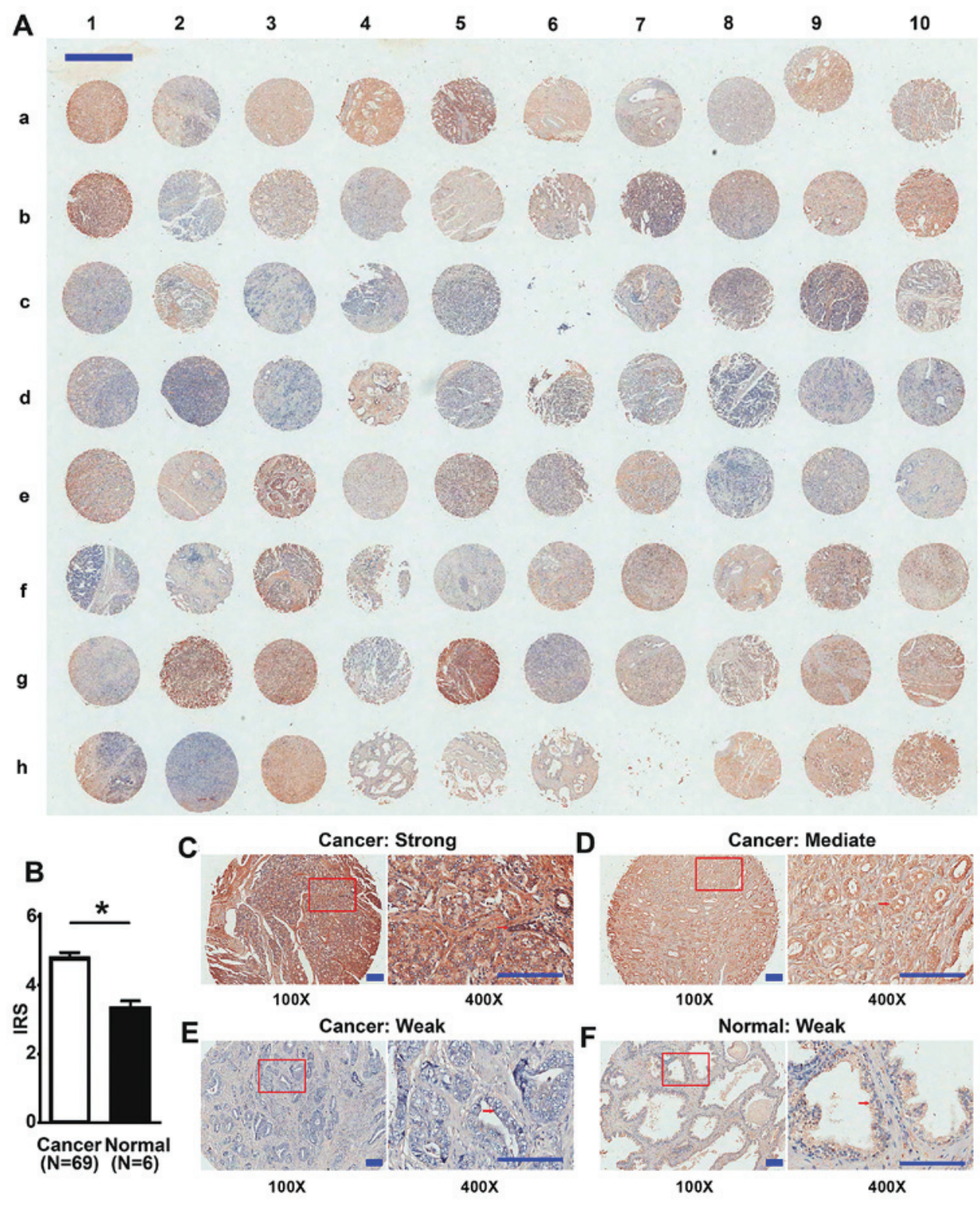

Figure 1. Immunohistochemical staining of DEPDC1B in tumor and normal prostate tissue samples, revealing that DEPDC1B protein is upregulated in tumor tissues from patients with PCa. (A) The whole scanned image of the tissue array. Scale bar, $1 \mathrm{~mm}$. (B) Statistical analysis demonstrating a higher IRS in tumor tissues compared with normal tissues, including adjacent normal prostate tissues, from patients with cancer and normal prostate tissues from healthy donors. ${ }^{*} \mathrm{P}<0.05$ vs. normal. Positive DEPDC1B staining with (C) strong, (D) intermediate and (E) weak expression levels in tumor tissues was observed in the cytoplasm. (F) Negative DEPDC1B staining in adjacent normal prostate tissue from a patient with PCa. Scale bars, $100 \mu \mathrm{m}$. DEPDC1B, DEP domain-containing protein 1B; PCa, prostate cancer; IRS, immunoreactivity score.

biomarkers for the treatment of patients with $\mathrm{PCa}$, as such markers may help to establish personalized treatment for each individual patient.

To the best of our knowledge, the present study is the first to investigate the association between DEPDC1B levels and clinical features of patients with PCa. Three main results were obtained by the present study. First, IHC was used to detect DEPDC1B protein levels in prostate tissues from patients with $\mathrm{PCa}$, and DEPDC1B protein levels were revealed to be higher in prostate cancer tissues compared with their adjacent non-cancerous or normal tissues. Second, to the best of our knowledge, the present study was the first to describe a significant association between DEPDC1B levels and Gleason score, clinical or pathological stage, lymph node metastasis and distant metastasis of patients with PCa. Third,
DEPDC1B mRNA levels were demonstrated to be significantly associated with the BCR-free survival time of patients with PCa. Kaplan-Meier analyses revealed that overexpression of DEPDC1B mRNA was associated with a significantly shorter BCR-free survival time, indicating that high levels of DEPDC1B mRNA are biomarkers for short BCR-free survival times of patients with $\mathrm{PCa}$. Multivariate analysis revealed that upregulation of DEPDC1B mRNA was a predictor of shorter BCR-free survival time independent from Gleason score. The results from the present study suggested that DEPDC1B may be involved in the aggressiveness of $\mathrm{PCa}$, and may provide useful information to help clinicians establish personalized treatment regimens for patients.

Previous expression profiling of DEPDC1B mRNA in MDA-MB 231 human breast cancer cells revealed an 
Table II. Prognostic value of DEPDC1B expression for BCR-free survival, assessed by Cox proportional hazards model.

BCR-free survival

Clinical features and DEPDC1B expression

$\operatorname{HR}(95 \% \mathrm{CI})$

P-value

Univariate analysis

Age, $\leq 60$ vs. $>60$ years

$1.055(0.539-2.066)$

0.875

PSA level, $\leq 4$ vs. $>4 \mathrm{ng} / \mathrm{ml}$

$1.588(0.658-1.588)$

0.304

Gleason score, $<7$ vs. $=7$ vs. $>7$

$7.361(4.025-13.46)$

$<0.001$

Pathological stage, pT2 vs. pT3/4

$5.232(2.564-10.68)$

$<0.001$

Clinical stage, $\leq \mathrm{T} 2 \mathrm{a}$ vs. T2b vs. $\geq \mathrm{T} 2 \mathrm{c}$

$0.943(0.822-2.559)$

0.831

Distant metastasis, M0 vs. M1

$21.15(10.27-43.54)$

$<0.001$

Lymph node metastasis, N0 vs. N1

$9.179(4.428-19.03)$

$<0.001$

DEPDC1B expression, low vs. high

$5.503(1.687-17.95)$

0.005

Multivariate analysis

Age, $\leq 60$ vs. $>60$ years

$0.697(0.264-1.838)$

0.465

PSA level, $\leq 4$ vs. $>4 \mathrm{ng} / \mathrm{ml}$

$0.546(0.235-1.269)$

0.160

Clinical stage, $\leq \mathrm{T} 2 \mathrm{a}$ vs. T2b vs. $\geq \mathrm{T} 2 \mathrm{c}$

$0.855(0.454-1.612)$

0.628

Gleason score, $<7$ vs. $=7$ vs. $>7$

$7.824(3.777-16.21)$

$<0.001$

DEPDC1B expression, low vs. high

$4.285(1.257-14.61)$

0.020

DEPDC1B, DEP domain-containing protein 1B; BCR, biochemical recurrence; PSA, prostate-specific antigen; HR, hazard ratio; CI, confidence interval.
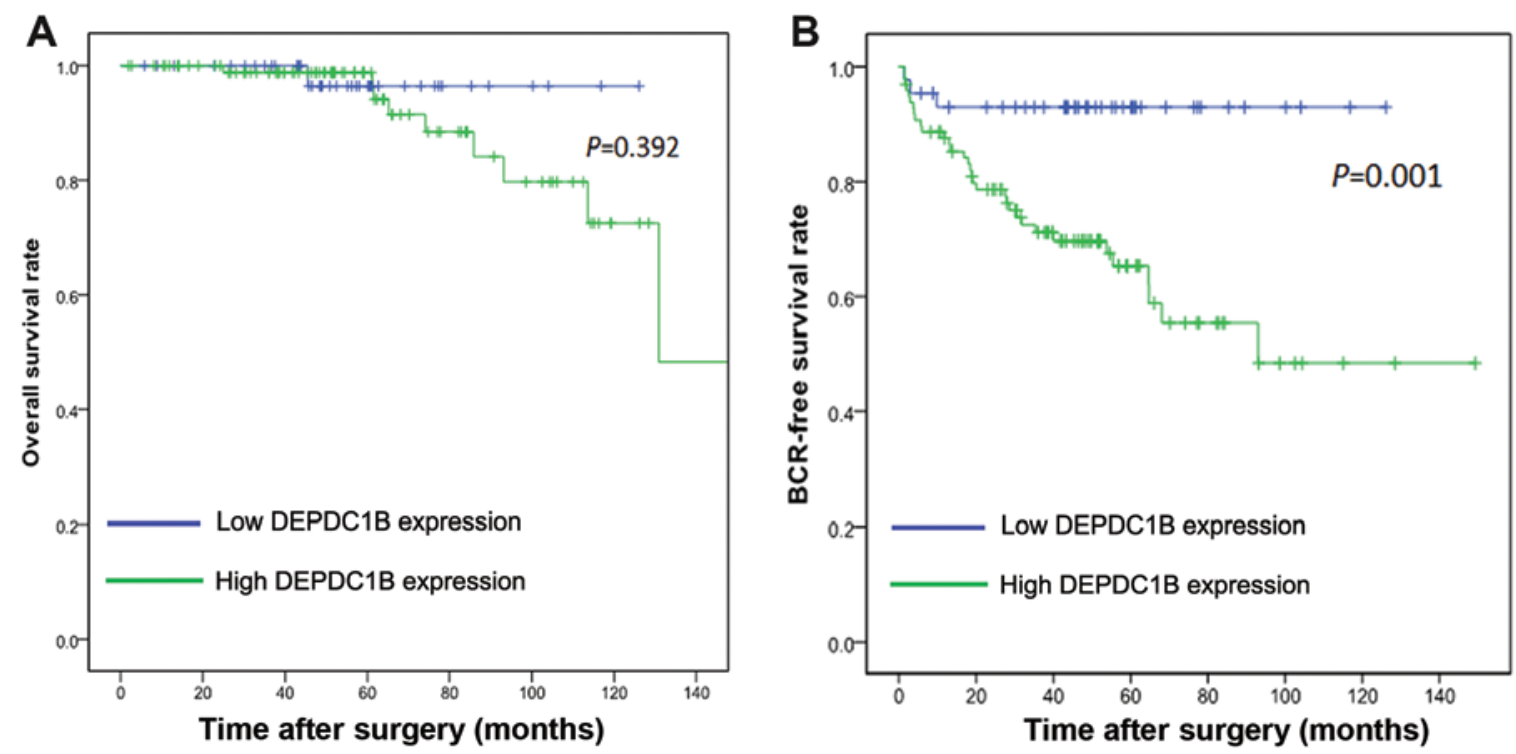

Figure 2. Kaplan-Meier survival curves assessing (A) overall survival times and (B) BCR-free survival times of patients with prostate cancer with high and low levels of DEPDC1B expression. Patients with high levels of DEPDC1B mRNA ( $\mathrm{n}=97)$ demonstrated significantly shorter BCR-free survivals than those with low levels $(\mathrm{n}=43 ; \mathrm{P}=0.001)$, however, the overall survival times between high and low levels of $\mathrm{DEPDC} 1 \mathrm{~B}$ had no significant difference $(\mathrm{P}=0.392)$. $\mathrm{BCR}$, biochemical recurrence; DEPDC1B, DEP domain-containing protein $1 \mathrm{~B}$.

association with a reduction in cell death and an increase in cell proliferation (12). DEPDC1B was also overexpressed in patients with oral cancer, and promoted cell migration and induced cell invasion in oral cancer cell lines (13). In addition, high levels of DEPDC1B expression contributed to metastasis-associated malignant phenotypes in non-small cell lung cancer (14). Although high levels of DEPDC1B expression were demonstrated in those types of cancer, it is not possible to consider them as independent prognostic factors. The present study demonstrated that DEPDC1B may be a good marker for the diagnosis or prognosis of $\mathrm{PCa}$. The high expression of DEPDC1B in $75.4 \%$ of prostate tissues from patients with $\mathrm{PCa}$ and little or no expression in normal prostate tissues suggested that an anti-DEPDC1B therapy would have minimal toxicity to normal prostate cells; and DEPDC1B expression levels demonstrated a significant 


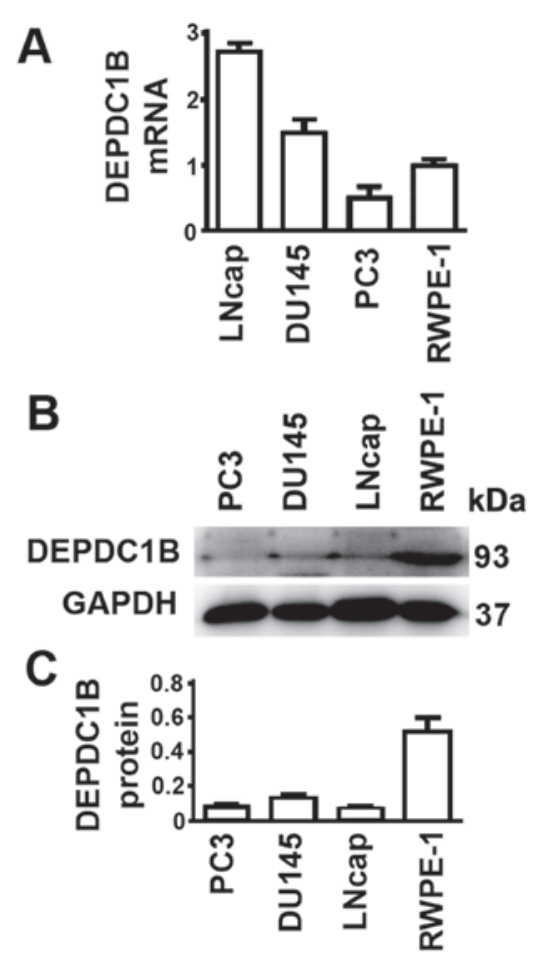

Figure 3. Levels of DEPDC1B mRNA and protein in normal prostate and cancer cell lines. (A) Relative levels of mRNA, as assessed by reverse transcription-quantitative polymerase chain reaction. (B) Representative results of western blotting and $(\mathrm{C})$ quantification of relative intensities of DEPDC1B protein. The intensities of the protein band were quantified using Image $J$ software and normalized by the levels of loading control GAPDH. Data are presented as the mean \pm standard deviation of at least three experiments. DEPDC1B, DEP domain-containing protein $1 \mathrm{~B}$.

association with BCR-free survival times of patients with PCa.

Despite the present understanding of the oncogenic function of DEPDC1B in prostate progression, it remains to be clarified how DEPDC1B, either directly or indirectly, affects the prognosis of patients with PCa. DEPDC1B protein contains DEP and RhoGAP conserved domains, which are involved in Rho GTPase signaling (19). Rho GTPases are best known for their regulation of cytoskeletal dynamics $(20,21)$. As major components of Rho GTPase signaling, Rho GTPase proteins, including ras homolog family member A (RHOA), ras-related C3 botulinum toxin substrate 1 ( $\mathrm{RAC} 1)$ and cell division cycle 42 (CDC42) are primarily activated by guanine nucleotide exchange factors (GEFs) and inactivated by GTPase-activating proteins (22-24). RAC1 and CDC42 regulate the formation of lamellipodia and filopodia, respectively, and promote protrusive activities; whereas RHOA regulates the formation of stress fibers and contractile rings (25). The stress fibers and the contractile rings are formed by actomyosin bundles with antiparallel actin filaments cross-linked by myosin (23). RHOA regulates these structures through the stimulation of actin polymerization and activation of myosin (26). Exogenous expression of DEPDC1B suppressed RAC1 activation, but did not markedly affect the activation of RHOA or CDC42 (27). Previous data indicated that actin is involved in the early stages of autophagosome formation $(28,29)$. In addition, RHOA and RAC1 were demonstrated to be involved in starvation-mediated autophagy, but serve opposite functions (30). Notably, autophagy marker LC3 binds to SOS Ras/Rac guanine nucleotide exchange factor 1 (SOS1), a GEF for RAC1, and inhibits the GEF activity of SOS1 to block RAC1 activation (31). Taken together, signals involved in the autophagic pathway and the RAC signaling pathway are mutually regulated (27). Therefore, it was suggested that different levels of DEPDC1B may affect the prognosis of patients with PCa through regulation of autophagy.

At present, due to the effect of patient age, prostate tumor size or other prostatic tissues in patients with $\mathrm{PCa}$, the value of PSA as a general biomarker is judged with skepticism $(32,33)$. The Gleason score has been demonstrated to be one of the reliable parameters for prediction of PCa progression (34). The present study demonstrated that levels of DEPDC1B expression may serve as an indicator for PCa BCR-free survival time, independent from Gleason scores. Additional tests concerning DEPDC1B may result in improved $\mathrm{PCa}$ treatment if it is able to distinguish patients who require additional treatment from those who only require monitoring. However, whether the assay is reproducible in other patients remains unknown. Since the data associated with protein and mRNA expression in the TMA and Taylor datasets was not matched, whether DEPDC1B protein is a prognosis marker remains inconclusive. Notably, $\mathrm{PCa}$ cell lines had lower DEPDC1B protein levels compared with the normal prostate cell line. It is possible that an unknown factor was suppressed in the tumor tissues but activated to a greater degree in cancer cell lines compared with the normal cell line. High levels of mRNA resulted in high levels of protein in tumor tissue samples, as expected. However, the unknown factor may have been more activated in PCa cell lines compared with the normal cell line, leading to faster degradation of the DEPDC1B protein and relatively lower levels of DEPDC1B protein in PCa cell lines compared with the normal cell line. Our future study will investigate this unknown factor. In addition, the data from the present study were unable to support the conclusion that the expression of DEPDC1B was a direct or indirect target of overall survival time. Larger cohorts and multicenter studies with profiles of protein and mRNA expression may demonstrate the significance and reliability of such a biomarker more effectively, and additional studies are required to decipher the mechanism by which DEPDC1B impacts survival time.

In conclusion, the present study offered convincing evidence for the first time that DEPDC1B protein was upregulated in tumor tissues. DEPDC1B mRNA was an independent prognostic factor for BCR-free survival time in patients with PCa. Overexpression of DEPDC1B was associated with Gleason score, clinical or pathological stage, lymph node metastasis and distant metastasis. The present study provided additional understanding of the mechanisms underlying $\mathrm{PCa}$, which may be helpful for the development of an effective therapeutic treatment.

\section{Acknowledgements}

The present study was supported by the National Natural Science Foundation of China (grant nos. 81472382 and 81672550), the National Natural Science Foundation of China for Young Scientists (grant no. 81101947), the Guangdong Province Natural Science Foundation (grant no. 2014A030313079), 
the Fundamental Research Funds for the Central Universities (grant no. 14ykpy19), Guangdong Province Science and Technology for Social Development Project (grant no. 201 3B021800107 and 2013B021800095), 2015 Guangzhou City Scientific Research Projects (grant no. 201510010298) and the International Science and Technology Cooperation Project of Guangdong Province Science and Technology Plan (grant no. 2016A050502020).

\section{References}

1. Siegel RL, Miller KD and Jemal A: Cancer statistics, 2016. CA Cancer J Clin 66: 7-30, 2016.

2. Chen W, Zheng R, Baade PD, Zhang S, Zeng H, Bray F, Jemal A, Yu XQ and He J: Cancer statistics in China, 2015. CA Cancer J Clin 66: 115-132, 2016.

3. Kristiansen G: Diagnostic and prognostic molecular biomarkers for prostate cancer. Histopathology 60: 125-141, 2012.

4. Ferlay J, Parkin DM and Steliarova-Foucher E: Estimates of cancer incidence and mortality in Europe in 2008. Eur J Cancer 46: 765-781, 2010

5. Shariat SF, Karakiewicz PI, Roehrborn CG and Kattan MW: An updated catalog of prostate cancer predictive tools. Cancer 113: 3075-3099, 2008.

6. Stephenson AJ, Scardino PT, Eastham JA, Bianco FJ Jr, Dotan ZA, DiBlasio CJ, Reuther A, Klein EA and Kattan MW Postoperative nomogram predicting the 10 -year probability of prostate cancer recurrence after radical prostatectomy. J Clin Oncol 23: 7005-7012, 2005.

7. Moyer VA; U.S. Preventive Services Task Force: Screening for prostate cancer: U.S. preventive services task force recommendation statement. Ann Intern Med 157: 120-134, 2012.

8. Sokol S: A role for Wnts in morpho-genesis and tissue polarity. Nat Cell Biol 2: E124-E125, 2000

9. Ballon DR, Flanary PL, Gladue DP, Konopka JB, Dohlman HG and Thorner J: DEP-domain-mediated regulation of GPCR signaling responses. Cell 126: 1079-1093, 2006.

10. Peck J, Douglas G IV, Wu CH and Burbelo PD: Human RhoGAP domain-containing proteins: Structure, function and evolutionary relationships. FEBS Lett 528: 27-34, 2002.

11. Martemyanov KA, Lishko PV, Calero N, Keresztes G, Sokolov M, Strissel KJ, Leskov IB, Hopp JA, Kolesnikov AV, Chen CK, et al: The DEP domain determines subcellular targeting of the GTPase activating protein RGS9 in vivo. J Neurosci 23: 10175-10181, 2003.

12. Boudreau HE, Broustas CG, Gokhale PC, Kumar D, Mewani RR, Rone JD, Haddad BR and Kasid U: Expression of BRCC3, a novel cell cycle regulated molecule, is associated with increased phospho-ERK and cell proliferation. Int J Mol Med 19: 29-39, 2007.

13. Su YF, Liang CY, Huang CY, Peng CY, Chen CC, Lin MC, Lin RK, Lin WW, Chou MY, Liao PH and Yang JJ: A putative novel protein, DEPDC1B, is overexpressed in oral cancer patients, and enhanced anchorage-independent growth in ora cancer cells that is mediated by Rac1 and ERK. J Biomed Sci 21: 67, 2014.

14. Yang Y, Liu L, Cai J, Wu J, Guan H, Zhu X, Yuan J and Li M: DEPDC1B enhances migration and invasion of non-small cell lung cancer cells via activating Wnt/ $\beta$-catenin signaling. Biochem Biophys Res Commun 450: 899-905, 2014.

15. Taylor BS, Schultz N, Hieronymus H, Gopalan A, Xiao Y, Carver BS, Arora VK, Kaushik P, Cerami E, Reva B, et al: Integrative genomic profiling of human prostate cancer. Cancer Cell 18: 11-22, 2010.
16. Lin ZY, Huang YQ, Zhang YQ, Han ZD, He HC, Ling XH, Fu X, Dai QS, Cai C, Chen JH, et al: MicroRNA-224 inhibits progression of human prostate cancer by downregulating TRIB1. Int J Cancer 135: 541-550, 2014.

17. Livak KJ and Schmittgen TD: Analysis of relative gene expression data using real-time quantitative PCR and the 2(-Delta Delta $\mathrm{C}(\mathrm{T})$ ) method. Methods 25: 402-408, 2001.

18. Jakobsen NA, Hamdy FC and Bryant RJ: Novel biomarkers for the detection of prostate cancer. J Clin Urol 9 (2 Suppl): S3-S10, 2016.

19. Burchett SA: Regulators of G protein signaling: A bestiary of modular protein binding domains. J Neurochem 75: 1335-1351, 2000.

20. Ridley AJ: Rho GTPases and actin dynamics in membrane protrusions and vesicle trafficking. Trends Cell Biol 16: 522-529, 2006.

21. Jaffe AB and Hall A: Rho GTPases: Biochemistry and biology. Annu Rev Cell Dev Biol 21: 247-269, 2005.

22. Schmidt A and Hall A: Guanine nucleotide exchange factors for Rho GTPases: Turning on the switch. Genes Dev 16: 1587-1609, 2002.

23. Hall A: Rho GTPases and the control of cell behaviour. Biochem Soc Trans 33: 891-895, 2005

24. Spiering D and Hodgson L: Dynamics of the Rho-family small GTPases in actin regulation and motility. Cell Adh Migr 5: 170-180, 2011.

25. Takeya R, Taniguchi K, Narumiya S and Sumimoto H: The mammalian formin FHOD1 is activated through phosphorylation by ROCK and mediates thrombin-induced stress fibre formation in endothelial cells. EMBO J 27: 618-628, 2008.

26. Sipos A, Iván J, Bécsi B, Darula Z, Tamás I, Horváth D, Medzihradszky KF, Erdódi F and Lontay B: Myosin phosphatase and RhoA-activated kinase modulate arginine methylation by the regulation of protein arginine methyltransferase 5 in hepatocellular carcinoma cells. Sci Rep 7: 40590, 2017

27. Wu D, Zhu X, Jimenez-Cowell K, Mold AJ, Sollecito CC, Lombana N, Jiao $M$ and Wei Q: Identification of the GTPase-activating protein DEP domain containing 1B (DEPDC1B) as a transcriptional target of Pitx2. Exp Cell Res 333: 80-92, 2015.

28. Köchl R, Hu XW, Chan EY and Tooze SA: Microtubules facilitate autophagosome formation and fusion of autophagosomes with endosomes. Traffic 7: 129-145, 2006.

29. Fass E, Shvets E, Degani I, Hirschberg K and Elazar Z: Microtubules support production of starvation-induced autophagosomes but not their targeting and fusion with lysosomes. J Biol Chem 281: 36303-36316, 2006.

30. Aguilera MO, Berón W and Colombo MI: The actin cytoskeleton participates in the early events of autophagosome formation upon starvation induced autophagy. Autophagy 8: 1590-1603, 2012.

31. Furuta S, Miura K, Copeland T, Shang WH, Oshima A and Kamata T: Light Chain 3 associates with a Sos1 guanine nucleotide exchange factor: Its significance in the Sos1-mediated Rac1 signaling leading to membrane ruffling. Oncogene 21: 7060-7066, 2002.

32. Diamandis EP: Prostate cancer screening with prostate-specific antigen testing: More answers or more confusion? Clin Chem 56: 345-351, 2010.

33. Kirby R: The role of PSA in detection and management of prostate cancer. Practitioner 260: 17-21, 3, 2016.

34. Leapman MS, Cowan JE, Simko J, Roberge G, Stohr BA, Carroll PR and Cooperberg MR: Application of a prognostic gleason grade grouping system to assess distant prostate cancer outcomes. Eur Urol 71: 750-759, 2017. 